\title{
EXPERIMENTAL AND NUMERICAL INVESTIGATION OF CEMENT PASTE MICROSTRUCTURE AND ITS HYDRATION UNDER SHORT-TERM EXPOSURE TO ACETONE
}

\author{
Yulita Khmurovska*, Petr ŠTemberk, JiŘí NĚmeČEK, \\ MagdalÉna DoležElová
}

\author{
Czech Technical University in Prague, Faculty of Civil Engineering, Department of Concrete Structures, \\ Thákurova 7, 16629 Prague 6, Czech Republic \\ * corresponding author: yuliia.khmurovska@fsv.cvut.cz
}

\begin{abstract}
The solvent exchange methods are commonly used in order to arrest cement hydration reaction. This paper presents preliminary results of experimental investigation of cement paste microstructure under short-term (24 hours) exposure to acetone as a solvent in order to estimate the influence of solvent soaking time. The methodology to determine the effect of soaking time based on numerical prediction is also presented and described. The immersion of cement samples with the cross-section of $10 \times 10 \mathrm{~mm}$ in acetone for 24 hours at the sample age of 15 hours does not enable to fully stop the hydration reaction, however, it can slow down the hydration reaction significantly. According to the comparison of several measured data (nanoindentation, scanning electron microscopy, observation made by optical microscope, mercury intrusion porosimetry) at the sample age of 1 month with the numerical simulation, the equivalent sample age is determined as approximately equal to 69 hours.
\end{abstract}

KEYwords: Acetone, cement paste, experiment, hydration reaction, numerical simulation.

\section{INTRODUCTION}

The hydration process of cement paste often has to be stopped in order to allow precise investigation and measurements of the alteration of cement paste properties over time. There are a numerous amount of methods to stop the hydration reaction [1-4], which can be divided into the following two groups:

(1.) Direct drying. The essence of the direct drying methods is to transform water into the vapor. The water vapor may escape freely and hydration reaction stops due to the lack of water, however, the direct drying methods are accompanied by the rapid change in temperature or pressure, which may damage microstructure of the sample or alter the cement paste properties and distort the results of the measurements [5 7]. The following types of direct drying are used in the available literature:

- oven drying [5, 8, 9],

- microwave drying [10 12,

- vacuum drying [13,

- freeze drying [14],

- D-drying 15,

- P-drying [15], etc.

(2.) Solvent exchange. The mechanism of solvent exchange methods is following: the solvent penetrates into the sample, mixes with free water and evaporates rapidly due to its low boiling point. It is believed that solvent exchange methods have lower impact on cement paste microstructure, however, it was reported [16, 17] that solvents may react with cement paste hydrates and alter its properties. Also, it is difficult to entirely remove solvents, therefore, the chemical composition of the cement paste may be affected by the solvent. The following types of solvents are used in the available literature:

- acetone [8, 18,

- methanol [19, 20,

- ethanol [21, 22],

- isopropanol [14, 19],

- tetrahydrofuran [1],

- dimethyl sulfoxid [20],

- benzene [16],

- pentane [23], etc.

From the above, it is obvious that the method to stop the hydration reaction should be chosen according to the subject of interest. This study is focused on cement paste microstructure investigation, therefore, the solvent exchange method was chosen and the acetone was used as the solvent.

The necessary solvent soaking time to stop the hydration reaction depends on many factors, such as porosity, diffusivity, sample cross-section. Porosity and diffusivity of early age cement paste change rapidly over time, therefore, the necessary solvent soaking time has to be a function of cement paste age. The majority of the research does not provide a sufficient explanation of the chosen soaking time. 
Another complication is that it is impossible to determine whether the reaction was stopped during the solvent soaking and the additional experiments are needed for this purpose. Therefore, the experimental investigation of the influence of solvents on cement paste has to be performed in order to determine the necessary solvent soaking time to stop the hydration reaction of early-age cement paste.

This paper presents preliminary results of the experimental investigation of early-age cement paste microstructure change under short-term (24 hours) exposure to acetone in order to estimate the influence of acetone soaking time. The methodology to determine the effect of soaking time based on the numerical prediction is also presented and described in detail below.

\section{EXPERIMENT}

The cement paste which consists of CEM I 42.5R EXTRACEM and water with water-to-cement ratio of 0.38 was used to produce small-scale $10 \times 10 \times 80 \mathrm{~mm}$ samples. The cement clinker composition is shown in Table 1. The samples together with the plexiglass moulds were insulated by polyethylene foil till the age of 15 hours.

After demoulding, all the samples were immersed in acetone for 24 hours at the sample age of 15 hours in order to stop the hydration process. After that all the samples were dried in oven at $50{ }^{\circ} \mathrm{C}$ till equilibrium in order to remove acetone. The samples were packed in polyethylene foil and were stored in box with silica gel until the examination in order to avoid possible moisture ingress 24.

Environmental temperature and relative humidity were recorded starting from the mixing till packing with the interval of 1 minute. The average environmental temperature was $20.7^{\circ} \mathrm{C}$ and relative humidity was $72.8 \%$ (excluding oven drying).

The amount of anhydrous clinker was obtained using three different techniques, namely, nanoindentation (NANO), scanning electron microscopy (SEM) and observation made by optical microscope (OPT) at the sample age of one month.

The surface of the sample sections, which were used for nanoindentation and SEM and OPT investigation, was polished with silica carbide paper to achieve a smooth surface. The nanoindentation of the polished sample sections was carried out with a Hysitron Tribolab Ti-700 with the Berkovich diamond tip. Five grids of $10 \times 10$ indents with the spacing of $10 \mu \mathrm{m}$ were predetermined on the center part of the sample surface. The nanoindentation was performed using the force control test with the trapezoidal loading diagram. The sample surface was loaded by the diamond tip linearly during three seconds till the maximum force of $2 \mathrm{mN}$ was reached with a following 20 seconds holding period and 3 seconds of unloading. The indentation elastic modulus was determined from the obtained load-displacement curves using the Oliver and Pharr theory 25]. The values of the elastic modulus higher than $50 \mathrm{GPa}$ and hardness higher than 1.5 GPa correspond to the anhydrous clinker.

After the nanoindentation, the polished sample sections were dried in a vacuum for three hours with a vacuum pump. The microstructure investigation of these sample sections was carried out by a Phenom XL Desktop SEM and optical microscope. The amount of anhydrous clinker was obtained using the image processing technique which was performed by the FIJI code. The measured volume fractions of anhydrous clinker and the average value are shown in Table 2

The sample porosity and its distribution was measured using mercury intrusion porosimetry (MIP) at the sample age of one month. The sample sections were broken into pieces and the center pieces were selected for further porosity investigation by the mercury porosimeter PASCAL 140 a 440. The measured porosity was in the range from $32.6 \%$ to $36.7 \%$ for different samples.

More detailed description of the experiment is given in 24].

\section{Numerical Simulation}

In order to understated whether the hydration reaction was fully stopped after the samples immersion in acetone, the MATLAB code of hydration and microstructure models, which is based on the models described in [26-28], was developed. The data presented in Table 1 and the measured environmental conditions were used in the analysis. The preliminary results are described below.

The degree of hydration was calculated using the multi-component model, where the rate of cement hydration heat generation is obtained from the sum of the hydration heat rates of cement components according to their proportions in cement. The degree of hydration was calculated according the following formula

$$
\alpha_{h y d}=\sum p_{i} \cdot\left(\bar{Q}_{i} / \bar{Q}_{i, \infty}\right)
$$

where $p_{i}$ is the mass ratio of the chemical component $i$ of cement (C2S, C3S, C3A, C4AF, gypsum, etc.), $\bar{Q}_{i}$ is the accumulated heat generation of the chemical component $i, \bar{Q}_{i, \infty}$ is the maximum theoretical specific heat of the component $i$ and $\alpha_{h y d}$ is the averaged degree of hydration.

The calculated degree of hydration of the individual clinker components and their average and time when the samples were immersed in acetone are shown in Figure 1] 24].

The cement paste microstructure was modeled using the expanding cluster model, volumetric balance and simplified calculation of the total pore surface area described in detail in $26+28$. After that the pore size distribution was calculated using a simplistic RaleighRitz distribution function. 


\begin{tabular}{llll}
\hline C3S, [\%] & C2S, [\%] & C3A, [\%] & C4AF, [\%] \\
\hline 63.99 & 14.30 & 9.11 & 8.26 \\
\hline
\end{tabular}

C3S: Alite; C2S: Belite; C3A: Celite; C4AF: Felite.

TABLE 1. Clinker composition of CEM I 42.5R EXTRACEM according to the manufacturer 24].

\begin{tabular}{llll}
\hline NANO, [\%] & SEM, [\%] & OPT, [\%] & Average, [\%] \\
\hline 18.40 & 18.30 & 18.89 & 18.53 \\
\hline
\end{tabular}

TABLE 2. Volume fractions of anhydrous clinker.

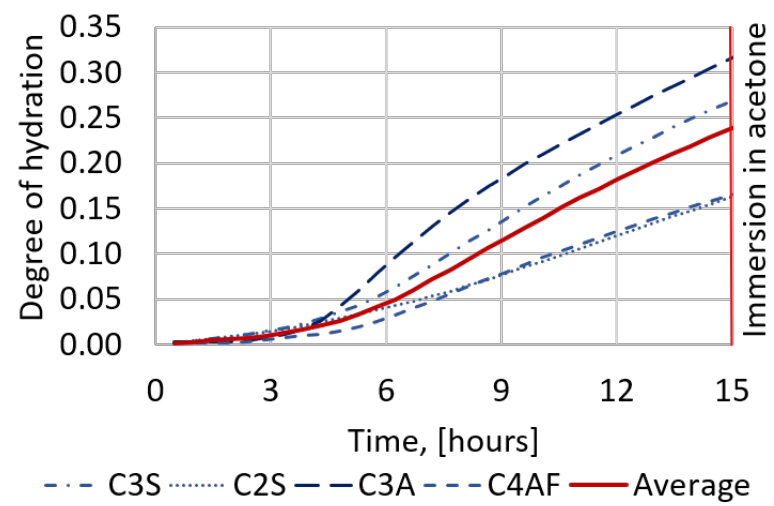

Figure 1. Calculated degree of hydration [24].

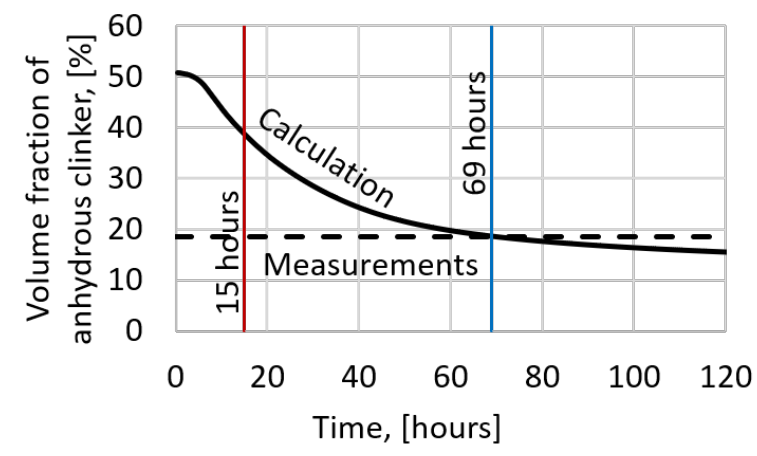

Figure 2. Amount of anhydrous clinker.

The volume fraction of anhydrous clinker was calculated as follows

$$
V_{c l}=\left(1-\alpha_{h y d}\right) \cdot W_{p} / \rho_{p}
$$

where $W_{p}$ is the weight of powder materials per unit paste volume, $\rho_{p}$ is the density of powder materials and $V_{c l}$ is the volume fraction of anhydrous clinker.

The decrease of the amount of anhydrous clinker due to the hydration reaction over time with the depiction of the averaged measured value is shown in Figure 2 24].

The capillary porosity was calculated using the following equation

$$
\phi_{c}=1-V_{s}-V_{c l},
$$

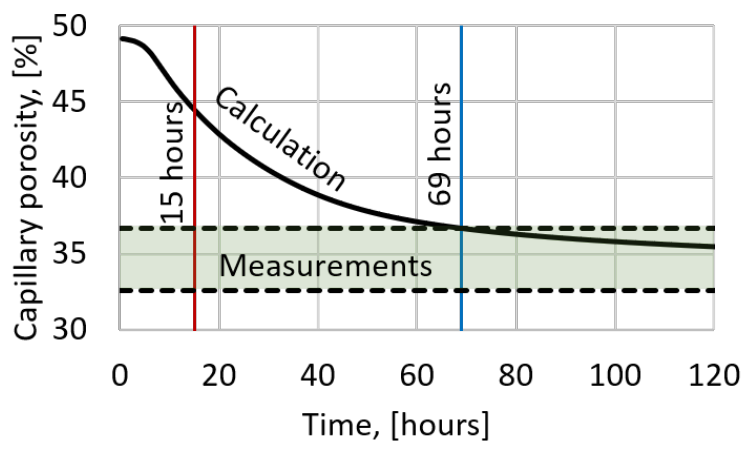

FIGURE 3. Capillary porosity.

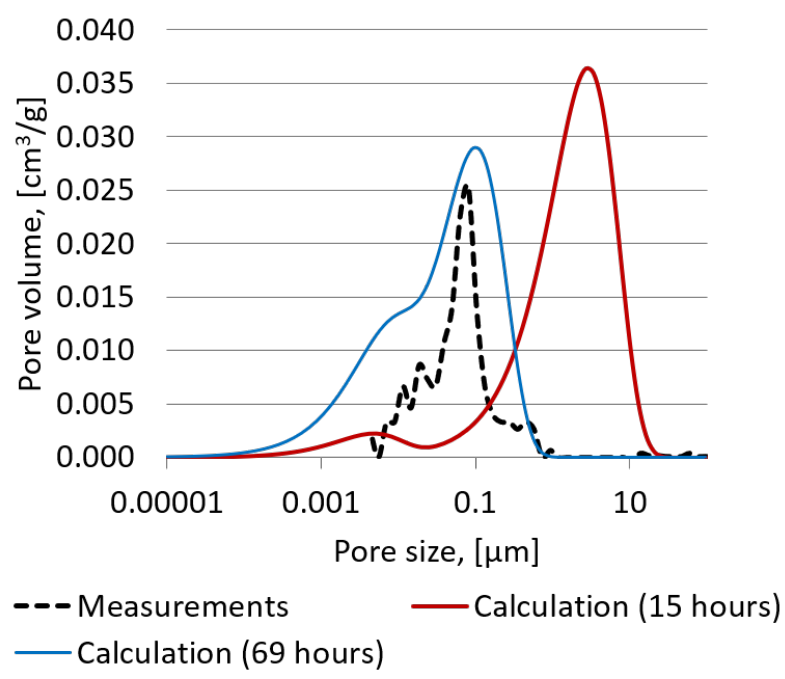

Figure 4. Pore size distribution.

where $V_{s}$ is the volume of hydrated products and $V_{c l}$ is the volume fraction of anhydrous clinker.

The pore size distribution was calculated as follows

$$
\phi(r)=\phi_{l}+\phi_{g} \cdot V_{g}+\phi_{c} \cdot V_{c}
$$

where $\phi_{l}, \phi_{g}$ and $\phi_{c}$ is the interlayer porosity, the gel porosity and the capillary porosity, respectively, $V_{i}=1-\exp \left(-B_{i} r\right)$ is the normalized pore volume, $B_{i}$ is the porosity distribution parameter and $r$ is the pore radius.

The calculated capillary porosity over time with the depiction of measured porosity (the total porosity 
obtained using MIP is considered to be predominantly capillary porosity) is shown in Figure 3, while the measured and calculated pore distribution are shown in Figure 4, 24].

As can be seen in Figure 2, Figure 3 and Figure 4 , the hydration reaction was not fully stopped at the sample age of 15 hours after sample immersion in acetone for 24 hours, but was slowed down significantly and the equivalent sample age is approximately equal to 69 hours according to the preliminary results of the numerical simulation at the real sample age of 1 month 24]. However, more detailed examination of the sample microstructure is still needed.

\section{Conclusions}

The immersion of cement samples with the crosssection of $10 \times 10 \mathrm{~mm}$ in acetone for 24 hours at the sample age of 15 hours could not fully stop the hydration reaction, however, it can slow down the hydration reaction significantly. According to the comparison of the measured data at the sample age of 1 month with the numerical simulation, the equivalent sample age is approximately equal to 69 hours. The calculated volume fraction of anhydrous clinker, capillary porosity and pore size distribution have a good correlation with the measured values. However, the additional experiments with the variable acetone soaking time and different sample cross-section are necessary in order to draw the final conclusions.

\section{LIST OF SYMBOLS}

$\alpha_{\text {hyd }}$ Averaged degree of hydration [-]

$\rho_{p} \quad$ Density of powder materials $\left[\mathrm{kg} \mathrm{m}^{-3}\right]$

$\phi_{c} \quad$ Capillary porosity $[-]$

$\phi_{g} \quad$ Gel porosity $[-]$

$\phi_{l} \quad$ Interlayer porosity [-]

$B_{i} \quad$ Porosity distribution parameter [-]

$\bar{Q}_{i}$ Accumulated heat generation of chemical component (C3S, C2S, C3A, C4AF) [kcal]

$\bar{Q}_{i, \infty}$ Maximum theoretical specific heat of component (C3S, C2S, C3A, C4AF) [kcal]

$V_{c l} \quad$ Volume of anhydrous clinker $\left[\mathrm{m}^{3} \mathrm{~m}^{-3}\right]$

$V_{s} \quad$ Volume of hydrated products $\left[\mathrm{m}^{3} \mathrm{~m}^{-3}\right]$

$V_{i} \quad$ Normalized pore volume $\left[\mathrm{m}^{3} \mathrm{~m}^{-3}\right]$

$W_{p}$ Weight of powder materials per unit paste volume $\left[\mathrm{kg} \mathrm{m}^{-3}\right]$

$p_{i}$ Mass ratio of chemical component of cement (C3S, C2S, C3A, C4AF) [-]

$r$ Pore radius $[\mathrm{m}]$

\section{ACKNOWLEDGEMENTS}

This work was supported by Ministry of Education, Youth and Sports of Czech Republic, project 8F17002, and the Czech Technical University, project SGS19/038/OHK1/1T/11, which are gratefully acknowledged.

\section{REFERENCES}

[1] J. Zhang, G. W. Scherer. Comparison of methods for arresting hydration of cement. Cement and Concrete Research 41(10):1024-1036, 2011. DOI:10.1016/j.cemconres.2011.06.003.

[2] L. D. Mitchell, J. C. Margeson. The effects of solvents on $\mathrm{C}^{-} \mathrm{S}-\mathrm{h}$ as determined by thermal analysis. Journal of thermal analysis and calorimetry 86(3):591-594, 2006. DOI:10.1007/s10973-006-7712-1

[3] J. J. Beaudoin, B. T. Tamtsia. Effect of drying methods on microstructural changes in hardened cement paste: an ac impedance spectroscopy evaluation. Journal of Advanced Concrete Technology 2(1):113-120, 2004. DOI:10.3151/jact.2.113

[4] M. Saraya. Stopping of cement hydration by various methods. HBRC Journal 6:36-60, 2010.

[5] C. Gallé. Effect of drying on cement-based materials pore structure as identified by mercury intrusion porosimetry: a comparative study between oven-, vacuum-, and freeze-drying. Cement and Concrete Research 31(10):1467-1477, 2001. DOI:10.1016/s0008-8846(01)00594-4

[6] L. Konecny, S. Naqvi. The effect of different drying techniques on the pore size distribution of blended cement mortars. Cement and concrete research 23(5):1223-1228, 1993. DOI:10.1016/0008-8846(93)90183-a

[7] R. J. Detwiler, L. J. Powers, U. H. Jakobsen, et al. Preparing specimens for microscopy. Concrete International 23(11):50-58, 2001.

[8] H. F. W. Taylor, A. Turner. Reactions of tricalcium silicate paste with organic liquids. Cement and Concrete Research 17(4):613-623, 1987. DOI:10.1016/0008-8846(87)90134-7

[9] K. K. Aligizaki. Pore structure of cement-based materials: testing, interpretation and requirements. CRC Press, 2005. DOI:10.1201/9781482271959

[10] M. Nagi, D. Whiting. Determination of water content of fresh concrete using a microwave oven. Cement, concrete and aggregates 16(2):125-131, 1994. DOI:10.1520/cca10290j

[11] W. Xuequan, D. Jianbgo, T. Mingshu. Microwave curing technique in concrete manufacture. Cement and Concrete Research 17(2):205-210, 1987. DOI:10.1016/0008-8846(87)90103-7

[12] T. E. Nantung. Determination of water-to-cement ratio in fresh concrete using microwave oven. Evaluation of SHRP Product 1998.

[13] S. Diamond. A discussion of the paper" effect of drying on cement-based materials pore structure as identified by mercury porosimetry-comparative study between oven-, vacuum-, and freeze-drying" by c. galle. Cement and concrete research 33(1), 2003. DOI:10.1016/s0008-8846(02)00940-7.

[14] R. L. Day, B. K. Marsh. Measurement of porosity in blended cement pastes. Cement and Concrete Research 18(1):63-73, 1988. DOI:10.1016/0008-8846(88)90122-6

[15] L. E. Copeland, J. C. Hayes. The determination of non-evaporable water in hardened portland cement paste. Tech. rep., 1953. 
[16] J. J. Beaudoin, P. Gu, J. Marchand, et al. Solvent replacement studies of hydrated portland cement systems: the role of calcium hydroxide. Advanced Cement Based Materials 8(2):56-65, 1998. DOI:10.1016/s1065-7355(98)00008-x.

[17] R. Day. Reactions between methanol and portland cement paste. Cement and Concrete Research 11(3):341349, 1981. DOI:10.1016/0008-8846(81)90106-x

[18] N. Collier, J. Sharp, N. Milestone, et al. The influence of water removal techniques on the composition and microstructure of hardened cement pastes. Cement and Concrete Research 38(6):737-744, 2008. DOI:10.1016/j.cemconres.2008.02.012

[19] R. F. Feldman, J. J. Beaudoin. Pretreatment of hardened hydrated cement pastes for mercury intrusion measurements. Cement and Concrete Research 21(23):297-308, 1991. DOI:10.1016/0008-8846(91)90011-6

[20] J. J. Beaudoin, B. Tamtsia, J. Marchand, H. R. Myers. Solvent exchange in partially saturated and saturated microporous systems: length change anomalies. Cement and concrete research 30(3):359-370, 2000. DOI:10.1016/s0008-8846(99)00260-4

[21] D. Hughes. The use of solvent exchange to monitor diffusion characteristics of cement pastes containing silica fume. Cement and Concrete Research 18(2):321324, 1988. DOI:10.1016/0008-8846(88)90016-6.

[22] H. C. Gran, E. W. Hansen. Exchange rates of ethanol with water in water-saturated cement pastes probed by nmr. Advanced Cement Based Materials 8(3-4):108-117, 1998. DOI:10.1016/s1065-7355(98)00013-3
[23] G. G. Litvan. Variability of the nitrogen surface area of hydrated cement paste. Cement and Concrete Research 6(1):139-143, 1976. DOI:10.1016/0008-8846(76)90058-2

[24] Y. Khmurovska. Influence of Neutron and Gamma Irradiation on Concrete Properties and Structural Performance. Czech Technical University in Prague. Ph. D. Thesis, 2019.

https://dspace.cvut.cz/bitstream/handle/10467/

85315/F1-D-2019-Khmurovska-Yuliia-PhDThesis\% 20Khmurovska.pdf? sequence $=-1 \&$ is sllowed $=y$

[25] W. Oliver, M. Pharr. An improved technique for determining hardness and elastic modulus using load and displacement sensing indentation experiments. Journal of Materials Research 7(6):1564-1583, 1992. DOI:10.1557/jmr.1992.1564.

[26] K. Maekawa, R. Chaube, T. Kishi. Modelling of concrete performance: Hydration, microstructure formation, and mass transport. E \& FN Spon, London, 1999. DOI:10.1201/9781482272161.

[27] K. Maekawa, T. Ishida, T. Kishi. Multi-scale modeling of concrete performance. Journal of Advanced Concrete Technology 1(2):91-126, 2003. DOI:10.3151/jact.1.91

[28] K. Maekawa, T. Ishida, T. Kishi. Multi-scale modeling of structural concrete. Crc Press, 2014. DOI:10.1201/9781482288599 